\title{
Innovation and Recent Development in Casting Techniques
}

\author{
Vigneshraj $\mathbf{C} \mathbf{T}^{1}$, Udayakumar $\mathrm{S}^{2}$ \\ ${ }^{1,2}$ R.M.K Engineering College, Department of Mechanical Engineering Chennai, India
}

\begin{abstract}
Metal casting processes are being adopted for manufacture of parts for equipment and machines for thousands of years. Over the years improvements and innovations have been deployed to make the processes more productive to increase output and at the same time making them cost effective. This paper describes three of the casting processes viz. Lost Foam Casting, Mould less Casting and Ice Casting Formation. The processes, the materials considered for the moulds, advantages and disadvantages as the case may be are

explained.
\end{abstract}

Keywords: casting, mould, die, foam, ice

\section{Introduction}

Innovation is the process of translating an idea or invention into a good or service that creates value or for which customers will pay. To be called an innovation, an idea must be replicable at an economical cost and must satisfy a specific need. Innovation involves deliberate application of information, imagination and initiative in deriving greater or different values from resources, and includes all processes by which new ideas are generated and converted into useful products.

Three of the metals casting process that will be discussed in this paperarelost foam casting; mold less casting and casting ice formation.

These original inventions have spawned large number of micro inventions and led to development of major industries they have spawned multi billion dollar industries. In short they have led to major innovations in casting field. Of the innumerable micro inventions in our field over these pastdecades some are of considerable industrial importance and others are practiced today only to limited extent but may someday occupy a prominent role in our industries

\section{Lost Foam Casting}

The Lost Foam Casting (LFC) process is a pioneering casting technique and an innovative alternative and addition to conventional foundry methods. It permits the production of complex components, and opens up new scope for casting.

\section{A. Process}

The first step in the process is pattern making. A pattern is made from polystyrene foam, which can be done inmany different ways. For small volume runs the pattern can be hand cut or machined from a solid block of foam; if the geometry is simple enough it can even be cut using a hotwire foam cutter. If the volume is large, then the pattern can be mass-produced by a process similar to injection molding. Pre-expanded beads of polystyrene are injected into a preheated aluminum mold at low pressure. Steam is then applied to the polystyrene which causes it to expand more to fill the die. [1] The final pattern is approximately $97.5 \%$ air and $2.5 \%$ polystyrene. Pre-made pouring basins, runners, and risers can be hot glued to the pattern to finish it.

In the next step, the foam cluster is coated with ceramic investment, also known as the refractory coating, via dipping, brushing, spraying or flowcoating. This coating creates a barrier between the smooth foam surface and the coarse sand surface. Secondly it controls permeability, which allows the gas created by the vaporized foam pattern to escape through the coating and into the sand. Controlling permeability is a crucial step to avoid sand erosion.

Finally, it forms a barrier so that molten metal does not penetrate or cause sand erosion during pouring. After the coating dries, the cluster is placed into a flask and backed up with un-bonded sand. The sand is then compacted using a vibration table. Once compacted, the mold is ready to be poured. Automatic pouring is commonly used in LFC, as the pouring process is significantly more critical than in conventional foundry practice.

There is no bake-out phase, as for lost-wax. To be sure that the desired result is achieved during series production, a consistent foam model quality is essential. The vital factor here is even density distribution and optimum welding together of the particle foam. When the molten metal meets the EPS model, the high temperature of the metal causes it to decompose into smaller fragments (depolymerization) and evaporate. The metal is then able to enter the vacated cavity
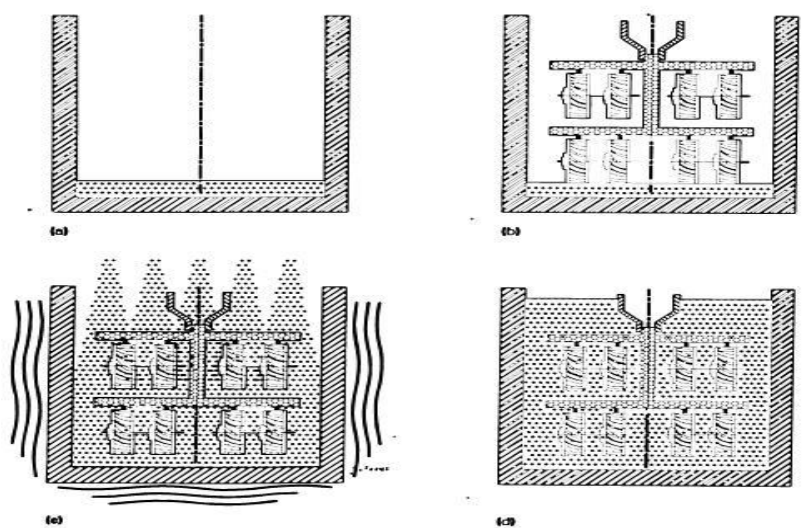

Figure 1: Lost foam casting 


\section{International Journal of Science and Research (IJSR) \\ ISSN (Online): 2319-7064}

Index Copernicus Value (2013): 6.14 | Impact Factor (2015): 6.391

Some benefits being Manufacture of complex components made of all commonly used alloys, Greater design freedom for designers than when casting in permanent molds, Undercuts, angled channels and contour-optimized cavities in the component are possible, Reduced number of machining processes, Use of rapid prototyping, Additional facility for weight reduction, clear production cost benefits, Very environmentally friendly process

Other benefits of this process for casting foundries is that it allows the reproduction of extremely complex components to be brought forward by a complete process: The problem of creating undercuts, angled channels and contour-optimized cavities is solved in advance by the foam model supplier. To achieve this, a foam model may need to be glued together from several individual segments. Using 3D CAD modeling, it is possible to determine how the overall mold must be divided into segments so that the position of the dividing seams does not impair the casting. At the same time, the dividing seams must be properly placed to ensure individual segment shapes which can be efficiently produced using the molding method.

Experience has shown the ideal gross density for moldings to be around 20 to $22 \mathrm{gr} / \mathrm{litre}$.

However the two main disadvantages are that pattern costs can be high for low volume applications and the patterns are easily damaged or distorted due to their low strength. If a die is used to create the patterns there is a large initial cost

\section{Mouldless Casting}

In the new method of rapid manufacturing, the molten metal is dropped on a substrate, making layers after another. This method has the potentiality to be used for complicated castings which are difficult to make their molds and patterns as usual ways. In droplet-based manufacturing process the castings are constructed by molten metal droplets having proper flow rate, temperature and diameter. In this paper a new system is designed and constructed which makes 3D parts and patterns by depositing molten metal droplets. Raw material wire melts and droplets are generated in droplet generating head. Molten metal Droplets deposit on a high temperature bed making the first layer. Next layers place on the previous ones to shape the final arbitrary part. These droplets are surrounded by natural air. Here tin60\%, lead40\% alloy wire is used. It is possible to apply other materials or wires having different diameters just with a little change in system. The wire is fed in special speeds which lead to different rates of droplets leaving the nozzle. Droplets have three properties which affect the layers and depositing way. These properties are droplet temperature and volume and their deposition rate. To control them several parameters of the system must be adjusted appropriately. At first it is assumed that these machine parameters are outlet nozzle diameter and feeding wire speed and also droplet temperature which affect droplet volume and deposition rate. Droplet temperature is measured exactly where they leave outlet nozzle. Droplet volume is estimated by several experiments, which lead to learn how different machine parameters create various droplet volumes. By knowing droplet volume and feeding wire speed, droplet rate can be calculated[2].

\section{ICE Casting Formation}

This study was designed to find improved materials and techniques for molding and casting natural or simulated ice shapes that could replace the wax and plaster method. By utilizing modern molding and casting materials a new methodology was developed that provides excellent reproduction, low-temperature capability, and reasonable turnaround time. The resulting casts are accurate and tough.

Recording the shapes of delicate ice accretions on aircraft components has always been a difficult task. Until now, ice formations were recorded primarily by using ice tracings or hot wax moldings. Use of tracings to record ice formations results in a loss of three-dimensional detail. Hot wax molding preserves much three-dimensional detail, but introduces new problem

The hot wax method calls for dipping a piece of ice (removed from the body on which it has accreted) into a container of molten beeswax. After a sufficient layer of wax has accumulated and after the ice has completely melted, the mold is opened and the water is drained. The mold is then filled with casting plaster that is allowed to harden. When the cast is solid, the wax is melted away, leaving a casting of the ice shape. This technique does not solve all the problems of molding and casting ice formations and even presents a few problems of its own. First, it is necessary to have a rather large piece of ice because the ice must be removed from the site on which it has accreted. This not only destroys information about the location of the ice formation relative to the body on which it was produced, but often damages the ice itself(which can be extremely fragile) and destroys any ice remaining on the body. Dropping a piece of ice into molten wax also has some effect on the ice shape. Second, using plaster as the casting material limits the value of the cast because its coarseness causes some surface texture and detail to be lost. Plaster is also inherently brittle, thus preventing the casts from being used in dry wind tunnel test programs for studying aerodynamic performance degradation due to icing

The goal of the work being reported herein was to achieve excellent reproduction of ice formations by utilizing modern molding and casting materials and techniques in place of hot wax and plaster. To do this, the mold must cure below 0 " $\mathrm{C}$ within a reasonable time, and the ice must also be allowed to remain on the body on which it has accreted. To ensure no ice melt, the curing process must not be at all exothermic. Temperature dependency is important in selecting a molding material. Molding materials are designed to cure at room temperature and may not cure below 0 "C the cast produced must retain. All the detail of the original ice formation and must be tough and merchantable to allow its use in dry wind tunnel testing

\section{A. Standard Handling Techniques for Handling Ice}

As stated previously, the ice that is s to be molded can often be extremely fragile. Any of the delicate horns associated with glaze ice, or the feathers associated with rime or mixed ice are easily broken. Therefore, it is s preferable not to 


\section{International Journal of Science and Research (IJSR) \\ ISSN (Online): 2319-7064 \\ Index Copernicus Value (2013): 6.14 | Impact Factor (2015): 6.391}

handle the ice at all, but to mold it at its accretion site another advantage of this method is that it preserves all the information about how the ice was oriented upon the body on which it was accreted. This method of molding at the site allows one to mold a small ice accretion, or even frost, that cannot be removed intact from the accretion site. When the ice cannot be molded at the site, great care must be taken to preserve as much ice detail as possible. If the ice has been accreted on a relatively small model, it would probably be best to remove and mold the entire model. The last resort would be to attempt to remove the ice from its accretion site and then mold only the ice itself. This can be done by slightly heating the body from which the ice is to be removed. If the mold cannot be poured immediately, the model should be placed in a plastic bag to prevent any sublimation and then placed in a freezer. A common picnic cooler containing dry ice can be used as a freezer. During handling, extreme care should betaken so as not to damage the ice

\section{B. Techniques for Molding}

In molding, all materials must be kept below 0 " $\mathrm{C}$ at all times. This requires a freezer large enough to keep all supplies refrigerated and also periodically re cooling materials being handled at room temperature. A digital scale for measuring the materials to be mixed is s also useful. The proportions of the various mold components are critical. Even as light change in the mixing ratio can greatly affect the properties of the mold

All the molding materials tested included a base material and a catalyst. Because these materials were being handled below their design temperatures, many became thick and difficult to handle. This necessitated using a thinning agent that allowed the materials to be poured while not interfering with their curing actions. During all testing, the procedures suggested by the material suppliers were followed, including(1) Using a high-quality digital scale for weighing proper amounts of base, curing agent, and thinner (2) Mixing all materials with a slow-speed electric-motor-driven impeller or a flat-bladed spatula to minimize air entrapment (3) De aerating all mixed compounds in a vacuum bell jar to remove air entrapped during mixing (4) Pouring the prepared molding compound carefully in order to avoid entrapping air

Every effort was made to minimize the exposure time at room temperature. The filled mold boxes were cured in the freezer at -5 "C to retain all ice sample details a freezer temperature of -5 " $\mathrm{C}$ was used for all molding operation. The base was mixed with the thinner first to allow the mixture to be re cooled after handling without any curing taking place since the catalyst had not yet been added. After this mixture was re cooled to below freezing, the required catalyst was added immediately after the catalyst was added and mixed thoroughly with the base and the thinner; the mixture was placed inside a bell jar and degassed for approximately 3 to 4 min or until little or no bubbling was taking place. These last two steps must be done skillfully for optimal results. The mixing must be done in such a way that as little air as possible is s introduced to the mixture so as to minimize the time required for degassing. The time is important since the mixture will be warming throughout the mixing and degassing and $\mathrm{w}$ ill need to be re cooled. The mixture will also be starting to cure. In the rare case in which a large amount of air is introduced to the mixture and a lengthy degassing is necessary, the materials may be cured to the point where they can no longer be poured by the time the mixture is re cooled to below 0 " $\mathrm{C}$.

After the compound is mixed, degassed, and re cooled, the mold may be poured. A mold box must have already been constructed to contain the molding materials. If the sample is $\mathrm{s}$ a small one that is $\mathrm{s}$ being molded away from it secretion site, care should be taken to prevent air from being trapped when the mold is s poured. This may happen if a fairly severe glaze ice formation is $\mathrm{s}$ to be molded and the sample is $\mathrm{s}$ oriented in the box with the leading edge down. The area between the horns of the ice shape could trap air and thus render the mold useless. This can be prevented by simply orienting the sample so that the leading edge is s pointing up. The mold should be poured carefully to help prevent mixing in any more air. Another problem may arise when the ice is $s$ removed from its accretion site. The sample must be physically held within the molding material or it will tend to float to the surface and ruin the mold. This can usually be done by placing several small rods across the mold box below the point to which it will be filled. To mold a small sample, the mold box should be immediately returned tithe freezer after the mold has been poured. The freezer may be reset to hold a temperature of just below freezing and the mold should remain undisturbed until cured. If the molding materials have been properly mixed, the condition of the entire mold can be determined by touching an exposed surface. If the mold seems solid to the touch, it may be removed from the freezer or the testing area and allowed to warm. After a reasonable time (usually about $2 \mathrm{hr}$ ) the mold may be pulled away from the test body. A small sample mold may be cut open to expose the area of the sample. Before casting a reproduction of the sample, allow the mold to dry thoroughly.

\section{Techniques for Casting}

Creating the cast is much simpler than producing the mold because there is no longer a need to keep the materials cold. The cast may be produced at any temperature. For many casting materials, heating the cast shorten curing time and strengthen the cast since temperature is no longer a prime concern, more care can be taken in mixing the casting materials. As with the molding materials, mixing the correct proportions of the various cast components is s important, and a digital scale should be used. Equally important is ensuring a complete and thorough mixing of the cast components. Several problems occur in the casting process. Since many of the materials are slightly toxic in their uncured state, they must be handled under an exhaust hood. Another possible problem is the distortion of the final cast because of incorrect orientation of the flexible mold during the cast cure this problem is s solved by returning the mold to the mold box within which was cured. The cast may be removed from the mold after the specified curing time the given cast material. If the mold is to be used for another casting extreme care should be used in removing the cast from the mold. Because roughness of the ice sample, it is often difficult to remove the cast without tearing the mold slightly. Although some damage cannot be completely avoided, it can be minimized by careful handling at this stage. At this point, an accurate model of the original ice formation has been 


\section{International Journal of Science and Research (IJSR) \\ ISSN (Online): 2319-7064}

Index Copernicus Value (2013): 6.14 | Impact Factor (2015): 6.391

obtained. This model can be used simply as a way of storing the icing phenomenon the geometry of the ice or as a test model in further studies of

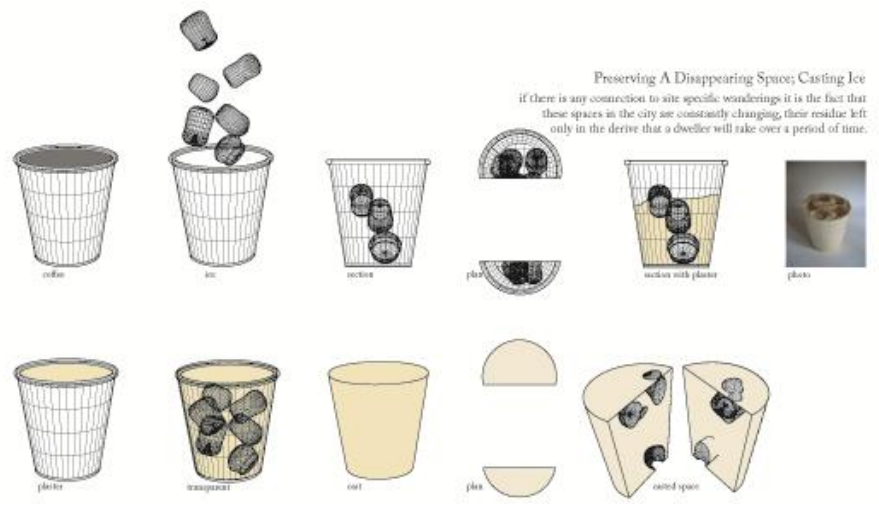

Figure 2: Ice casting forming

\section{Materials Considered}

Silicone rubber compounds were chosen for molding operations, and epoxy and urethane compounds for casting operations. The properties sought in these materials and the benefits derived from these properties are given for both the molding and casting materials in table I.[3] The most current information on these properties was obtained from DowCorning Corp. and General Electric Co. for their respective mold-making com-pounds and from Ciba-Geigy Corp. and Hexcel Corp. for epoxy and urethane casting materials.

Excellent detail of ice formations can be reproduced in molds by using the proper materials and techniques. The experiments demonstrated that it is possible to use a silicone rubber molding material below 0 " $\mathrm{C}$ and still have reasonable curing times. It has also been shown that an accurate, tough, and merchantable permanent model of ice formations can be cast from previously produced molds through the use of selected urethanes and epoxies

A new process that is just entering production is the "SLIC" process developed y metal casting technology, a joint venture of General motors and Hitchiners mfg.co., development of this process was undertaken with the aim of producing steel automotive castings in high volume and at low cost was undertaken with the aim of producing steel automotive castings in high volume and at low cost that would have many of the advantages normally associated with investment casting: dimensional accuracy, surface finish, integrity and thin sections. The process combines aspects of investments casting and lost foam casting. To avoid long heating sections, the mold is heated from inside out. The process starts with a foam polymer "tree" containing multiple foam patterns and coating this as in investment casting, to obtain a relative thin shell, the tree is then backed by loose sand and heated internally until the pattern is fully removed and the inner section of the mold has been heated to the desired temperature for casting. Casting is then done by counter gravity. The process has the potential to bring many of the advantages of investment casting to the automotive market along with substantial reduced cost and energy usage.

\section{Conclusion}

In this paper the design essence of the constructed droplet based manufacturing machine is told. And dependency of droplet properties to machine adjustments is studied. Study on lost foam casting and casting ice formation was also made successfully.

Thus these casting process are few of the innovations that have taken place in recent history in the field of casting.

\section{References}

[1] Andrew L. Reehorst and G. Paul Richter-New methods of ice mold casting

[2] Wikipedia- Casting techniques

[3] Leyland S, Jones S. The Effect of Drying Conditions upon the Wax/ceramic Interface Temperature. 8th International Symposium on Investment Casting

[4] Degarmo, E. Paul; Black, J T.; Kohser, Ronald A. (2003), Materials and Processes in Manufacturing (9th ed.), Wiley, p. 277, ISBN 0-471-65653-4

[5] Ravi, B. (2005), Metal Casting: Computer-Aided Design and Analysis (1st ed.), PHI, ISBN 81-203-27268

[6] Campbell, John (1993). Castings. ButterworthHeinemann.p. 49. ISBN 0-7506-1696-2.

[7] Sand Casting Process Description

[8] Todd, Allen \&Alting 1994, pp. 256-257.

[9] Degarmo, Black \&Kohser 2003, p. 311.

[10] Rao 2003, p. 18.

[11] Degarmo, Black \&Kohser 2003, p. 300. 